\title{
Formation of costs of high-rise objects of housing and civil purpose based on enlarged norms
}

\author{
Anna Vorotyntseva $^{1, *}$ Andrei Ovsiannikov ${ }^{1}$, and Vladimir Bolgov ${ }^{1}$ \\ ${ }^{1}$ Voronezh State Technical University, Moscow Avenue, 14, Voronezh, 394026, Russia
}

\begin{abstract}
When determining the cost of capital construction objects, for purposes of pre-design workings out and purposes of initial maximum initial price determination on tenders, construction price norms are used (CPNs). Modern CPNs are not designed to determine the value of high-rise buildings. It is necessary to adapt modern CPNs to get opportunity for the possibility to take into account special cost factors in determining the cost of high-rise buildings. The main ways can be: selection of new representative objects or application of additional correction factors.
\end{abstract}

\section{Introduction}

International experience of building modern cities shows that, because of high land cost and high density of construction the most justified from an economic point of view are buildings ranging in height between 30 to 50 floors. That is why high-rise building construction is a priority in modern urban environment. Implementation of high-rise construction in large cities is dictated by a high deficit of the territory for construction, including a deficit of office and hotel areas, which it is more reasonable to place in highrise buildings. In Russia, high-rise construction has not yet become as widespread as in the west, but nevertheless is developing actively. This is confirmed by a number of completed projects in Russian cities [1,2].

Construction of high-rise buildings for housing and civil purposes is a huge multi-stage process, in which, at the planning stage of future work, it is often necessary to know how much the construction of the planned project will cost. At present, the task of developing and introducing aggregated cost indicators of construction of buildings and structures to the construction industry is more acute than ever. The need to use such indicators is dictated by emerging economic issues at the stages of developing an investment project. The most convenient option in this situation is the compilation of an estimate for the aggregated standards for the price of constructive solutions (SPCS) and construction price norms (CPNs), which allows the maximum construction cost to be determined as accurately as possible without making a detailed estimate [3]

What is the difference between SPCS and CPNs, and on what stages are they necessary?

\footnotetext{
* Corresponding author: allslavin@mail.ru
} 


\section{Materials and Methods}

Standards for the price of constructive solutions (SPCS) - show the amount of funds to build separate construction elements of the object calculated per unit of measurement. SPCS are used at the design stage as a rule.

CPNs at its turn - show the amount of funds necessary and sufficient to build capital building object, calculated per unit of measurement. CPNs are used in the planning, investment and design stages. In this article we will consider the purpose and technology of compiling budget estimates with the help of CPNs for building construction as a whole. Also we will find out why is necessary to use it.

CPNs compilations are used for:

- investment planning for capital investments;

- assessment of the effectiveness of the use of funds directed to capital investments;

- preparation of technical and economical significates in the designing task;

- investment project design

- justification of the cost of construction;

- minimization of subjective indicators in the valuation of construction objects.

CPNs were developed and approved on the basis of design estimates for facilities were developed and approved on the basis of design estimates for facilities designed and built in the Russian Federation in the period from 1995-2009. Primary information was collected on a large number of objects of various functional purposes, and then a thorough analysis of design estimates for these facilities was carried out. As a result, the basis of CPNs development is the data that had passed the expertise and met the town-planning and space-planning requirements, imposed on modern construction complexes and facilities. It resulted in adoption of the order of Ministry of Regional Development of Russian No. 187 at 22.04.2011 «About approval of enlarged standards for the price of construction of various types of capital building projects for non-production purposes and engineering infrastructure" with prices for January 1, 2011». Later these norms documents were updated and supplemented. Next norms were approved by the order of the Ministry of the Region of Russian Federation No. 643 at 30 December of 2011. They contain prices for January 1, 2012. CPNs - 2014, approved by the order of Ministry of Construction Housing and Communal Services of Russian Federation at 28.08.2014 No.506. Currently, there are norms approved by Ministry of Construction at 13 June 2017 No. 867. At present, the computation of the estimate for CPNs is made in prices for 2017. It should also be borne in mind that all prices in the enlarged norms are taken for the base (Moscow) region, respectively, for calculations on other territories, it is necessary to apply the transition coefficient from the prices of the base region to the price of the subjects of the RF $[4,5]$.

Depending on the functional purpose all CPNs are combined in collections:

CPNs 81-02-01-2017 «Apartment buildings»

CPNs 81-02-02-2017 «Administrative buildings»

CPNs 81-02-03-2017 «Objects of public education »

CPNs 81-02-04-2017 «Health facilities»

CPNs 81-02-05-2017 «Sports buildings and facilities»

CPNs 81-02-06-2017 «Objects of culture»

CPNs 81-02-07-2017 «Railways»

CPNs 81-02-08-2017 «Highways»

CPNs 81-02-09-2017 «Bridges and overpasses»

CPNs 81-02-10-2017 «Metro objects»

CPNs 81-02-11-2017 «Outdoor communication networks»

CPNs 81-02-12-2017 «Outdoor electrical networks» 
CPNs 81-02-13-2017 «Outdoor thermal networks»

CPNs 81-02-14-2017 «Water supply and sewerage networks»

CPNs 81-02-15-2017 «Gas supply networks»

CPNs 81-02-16-2017 «Small architectural forms»

CPNs 81-02-17-2017 «Planting of greenery»

CPNs 81-02-18-2017 «Civil aviation objects»

CPNs 81-02-19-2017 «Urban Infrastructure Buildings and Structures»

CPNs 81-02-20-2017 «Objects of sea and river transport»

CPNs 81-02-21-2017 «Energy facilities (except for linear ones)».

\section{Results}

The use of compilations and the compilation of calculations for NDCs is regulated by the MDS 81-02-12-2011 "Methodological recommendations on the application of state estimate standards - enlarged standards for the price of construction of various types of capital construction facilities for non-production purposes and engineering infrastructure" approved by the order of the Ministry of Regional Development of the Russian Federation of October 4, 2011 No. 481.

When using CPNs it is necessary to keep in mind what costs it includes [6]:

- costs for the construction of capital building projects that meet the urban planning and space planning requirements for modern facilities, as well as the costs of construction of individual buildings and structures designed using standard (reusable) design solutions;

- costs provided by the current normative documents in the field of pricing for the performance of work in the construction of the facility in normal (standard) conditions, not complicated by external factors;

- costs for the purchase of building materials and equipment, costs for labor remuneration for workers and maintenance of construction machinery (mechanisms), overheads and estimated profits, costs for the construction of temporary buildings and structures, additional costs for the production of work in winter, costs connected with receipt by the customer and project organization of initial data and specifications for design, carrying out the necessary approvals for project solutions, expenses for insurance (including construction risks); costs for design and survey work and project expertise, customer service content and construction control, reserve funds for unforeseen work and costs.

It is necessary to keep in mind that cost parameters of CPNs are not taken into account, and, if necessary, should be taken into account separately:

- works and costs associated with the allocation of land for construction, travel expenses of workers, transportation of workers, construction and maintenance costs of shift camps, land tax payments during construction, fees for connection to external engineering networks;

- additional costs, arising under special construction conditions (in remote settlements from the existing infrastructure (additional transportation costs), cramped working conditions), which should be taken into account additionally. Special conditions for the construction of the facility are taken into account by the coefficients provided in the technical parts of the collections of the CPNs. Additional transportation costs are accounted with the use of zonal coefficients for changing the cost of construction in context of the 
subject of Russian Federation specified in Appendix No. 2 to this Methodological Recommendations.

To calculate the cost of construction of high-rise buildings for civil purposes, it is necessary to take into account structural features of buildings. High-rise buildings have different purposes: hotels, offices, residential buildings. Most often high-rise building is multifunctional, in addition to premises of main purpose it also has parking lots, shops, offices and cinemas. High-rise building also has its own structural features of the main bearing elements, which depend on the specific weight of the cost of structures and types of work.

How can we calculate the cost of planned for construction object, using CPNs? Recommended for calculations formula is contained in MDS :

$$
C_{f i}=\left[\left(\sum_{i=1}^{n} C P N_{i} \cdot P \cdot K_{C} \cdot K_{t r} \cdot K_{r e g} \cdot K_{\text {zone }}\right)+Z_{p}\right] \cdot I_{f i}+V A T
$$

where:

$C P N_{i}$ - used index of the state estimate norm - the enlarged norm of the construction price for a specific facility for the base district (Moscow region) at the price level at the beginning of the current year;

$\mathrm{N}$ - total number of used indexes of the state estimate norms - an aggregate construction price norm for a specific facility for the base district (Moscow region) in the price level at the beginning of the current year;

$P$ - capacity of the object planned for construction (total area, number of places, length, etc.);

$I_{f i}-$ forecast index, it is determined basing on indexes of manufacturers prices by types of economic activity in line «Capital Investments» which are used to forecast social and economic development of Russian Federation;

$K_{t r}$ - coefficient of transition from the prices of the base district (Moscow region) to level of prices of subjects of Russian Federation, it is used to calculate planned cost of construction of facilities which are financed by federal budget funds, also it is determined basing on state estimated norms - Construction Price Norms. The value of this transition coefficients is set annually by the orders of Ministry of Regional Development of Russia;

$K_{\text {reg }}-$ coefficient, which considers climatic conditions of region of construction (differences in constructive decisions) in regions of Russian Federation comparing to basic region;

$K_{C}$ - coefficient, which characterizes rise in cost of construction in seismic regions of Russian Federation;

$K_{\text {zone }}$-zoning coefficient, which considers difference in resources cost in region;

$Z_{p}$ - additional costs, which are considered as separate calculation, in order, which is conditioned by construction production cost determination method on Russian Federation's territory MDS 81-35.2004, , approved by the Resolution State Committee of Russian Federation on 5 March 2004;

$Z_{p}$ - additional costs, which are considered as separate calculation, in order, which is conditioned by construction production cost determination method on Russian Federation's territory MDS 81-35.2004, , approved by the Resolution State Committee of Russian Federation on 5 March 2004, 15/1;

VAT - value-added tax, currently $18 \%$.

Existing approach does not allow to calculate the cost of high-rise buildings of civil purpose, due to the lack of developed standards for construction prices.

There are different types of high-rise residential multi-apartment buildings:

- Residential multi-apartment high-rise building (more than 16 floors) bricked, mono carcassed; 
- Residential multi-apartment high-rise building (more than 16 floors) paneled [7].

For object of other types there is no calculation of altitude. It is necessary to develop CPNs for most common types of objects:

- residential houses;

- administrative buildings;

- trade objects - shopping centers;

- combined objects of different functional orientation.

It is necessary to develop CPNs in one of directions:

1. Definition of representative-objects from high-rise ones.

2. To use coefficient method of cost accounting.

In case of using first method it will not have any differences from existing ones. It is only necessary to demarcate the gradation of high-rise objects correctly - to combine representative-objects in different high-rise groups and update current CPNs.

To calculate the altitude of objects with second method following approach is proposed $[8,9,10]$.

The cost of base object of construction is calculated with next formula:

$$
C_{o b j}=\left(\sum_{i=1}^{n} C P N_{i} \cdot S_{i}\right) \cdot K^{a l t}
$$

where:

$C P N_{i}$ - used index of the state estimate norm - the enlarged norm of the construction price for every type of object (Residential buildings, Health facilities, Sports buildings and structures, Cultural objects), included in the object;

$S_{i}-$ specific weight of the i-th type of object in total volume of construction of the facility;

$K^{\text {alt }}$ - coefficient of «altitude» of object, which considers the ratio of the building area and the total area of the building. This coefficient is important to This coefficient is necessary to exclude the individual "duplicated" types of work (foundations) considered in each i-th kind of object.

\section{Conclusion}

In conclusion it will not be wrong to say that calculations made with CPNs collections are very important on planning stage, design stage and investing of high-rise buildings of civil purpose stage.

When considering issues of construction residential buildings, health and cultural facilities, external engineering networks, roads, etc. customer can estimate how much it will cost to erect a particular building and structure, by using the collections of CPNs, which is an actual task in the conditions of limited budget funds.

\section{References}

1. Mir M. Ali. Evolution of Concrete Skyscrapers: from Ingalls to Jin mao Electronic Journal of Structural Engineering. 1(1) (2001)

2. J. Orgill-Meyer, M. Jeuland, J. Nathan Cutler., Ecological Economics,Volume 146, Pages 250-264, (2018)

3. A. Vorotynseva A. Ovsiannikov V. Bolgov MATEC Web of Conferences, 106 (2017) 
4. O.V. Didkovskaya, O.A. Mamayeva, M.V. Ilyina. Procedia Engineering, 153, pp 131135. (2016)

5. T. Ahmad, A. Aibinu, M. Jamaluddin Thaheem. Procedia Engineering, 180, pp 16951704. (2017)

6. V. Zahirovich-Herbert, K. M. Gibler. Journal of Housing Economics, 26, P.1-18 (2014)

7. S. Uvarova, S. Belyaeva, L. Myshovskaya, IOP Conference Series: Earth and Environmental Science. 90(1), 012169. 2017

8. S. Belyaeva, D. Voronov, S. Erypalov. MATEC Web of Conferences. 106, 08033. (2017)

9. N. Safronova, E. Nezhnikova, A. Kolhidov MATEC Web of Conferences 10608024 (2017) doi: 10.1051/matecconf/201710608024

10. V. Kankhva, Procedia Engineering $165 \quad 1300-1304 \quad$ (2016) doi:10.1016/j.proeng.2016.11.855 